\title{
Stereoelectroencephalography in epilepsy,
}

\section{cognitive neurophysiology, and psychiatric disease: safety, efficacy, and place in therapy}

This article was published in the following Dove Press journal:

Neuropsychiatric Disease and Treatment

\author{
Brett E Youngerman \\ Farhan A Khan \\ Guy M McKhann
}

Department of Neurological Surgery, Columbia University Medical Center, New York, NY, USA
Correspondence: Brett E Youngerman Department of Neurological Surgery, Columbia University Medical Center, 710 West 168th Street, New York, NY 10032, USA

Tel +I 5169642145

Email bey2103@cumc.columbia.edu

\begin{abstract}
For patients with drug-resistant epilepsy, surgical intervention may be an effective treatment option if the epileptogenic zone (EZ) can be well localized. Subdural strip and grid electrode (SDE) implantations have long been used as the mainstay of intracranial seizure localization in the United States. Stereoelectroencephalography (SEEG) is an alternative approach in which depth electrodes are placed through percutaneous drill holes to stereotactically defined coordinates in the brain. Long used in certain centers in Europe, SEEG is gaining wider popularity in North America, bolstered by the advent of stereotactic robotic assistance and mounting evidence of safety, without the need for catheter-based angiography. Rates of clinically significant hemorrhage, infection, and other complications appear lower with SEEG than with SDE implants. SEEG also avoids unnecessary craniotomies when seizures are localized to unresectable eloquent cortex, found to be multifocal or nonfocal, or ultimately treated with stereotactic procedures such as laser interstitial thermal therapy (LITT), radiofrequency thermocoagulation (RF-TC), responsive neurostimulation (RNS), or deep brain stimulation (DBS). While SDE allows for excellent localization and functional mapping on the cortical surface, SEEG offers a less invasive option for sampling disparate brain areas, bilateral investigations, and deep or medial targets. SEEG has shown efficacy for seizure localization in the temporal lobe, the insula, lesional and nonlesional extra-temporal epilepsy, hypothalamic hamartomas, periventricular nodular heterotopias, and patients who have had prior craniotomies for resections or grids. SEEG offers a valuable opportunity for cognitive neurophysiology research and may have an important role in the study of dysfunctional networks in psychiatric disease and understanding the effects of neuromodulation.
\end{abstract}

Keywords: stereoelectroencephalography, SEEG, epilepsy surgery, cognitive neurophysiology, psychiatric neurosurgery

\section{History}

Approximately $30 \%$ of the patients with epilepsy have seizures refractory to antiepileptic drugs despite optimal management. ${ }^{1,2}$ After unsuccessful trials of two medications, the likelihood of achieving seizure freedom with a third is less than $4 \%$. In such patients with drug-resistant epilepsy, ${ }^{3}$ surgical intervention may be an effective treatment option if the seizure onset zone can be well localized. In some cases, where seizure semiology, noninvasive scalp EEG, and imaging concordantly suggests a clear epileptogenic zone (EZ) in a surgically accessible region, a resection or other targeted procedure can be performed with reasonable confidence. However, when there is discordant information, multiple potential foci, or 
nearby eloquent cortex, intracranial implantation of electrodes and extra-operative mapping of the seizure onset zone can aid in further treatment planning. ${ }^{4}$

Subdural electrodes (SDE) have been the seizure mapping approach of choice for decades in the United States. Strips and grids of electrodes are placed in the subdural space through a craniotomy or burr holes, allowing for electrocorticography and localization of seizure onsets on the cortical surface. Otfrid Foerster and Hans Altenburger introduced SDE in 1935 and were the first to describe an ictal seizure pattern. ${ }^{5}$ Wilder Penfield and Herbert Jasper built upon these findings two years later by incorporating neural stimulation. ${ }^{6}$ This development allowed for the identification and preservation of functionally critical cortical areas. Since then, procedural standards have evolved to include extensive preoperative planning, tailored craniotomies or burr-holes, and focused placement of modernized strips and/or grids. ${ }^{7}$ The technique has frequently been combined with the use of select depth electrodes to sample deeper brain structures such as the hippocampus, but SDE remained the foundation of intracranial seizure monitoring in the United States.

Stereoelectroencephalography (SEEG) is an alternative approach to intracranial monitoring in which depth electrodes are placed through percutaneous twist drill holes to stereotactically defined coordinates in the brain and secured at the skull. Jean Talairach and Jean Bancaud developed SEEG between 1957 and the early 1970s at Hospital Saint Anne, Paris. ${ }^{8}$ Early SEEG innovators placed the electrodes using frame-based stereotactic systems. A Talairach stereotactic frame and double-grid system were applied under anesthesia. ${ }^{9}$ To avoid damage to vascular structures, diagraming trajectories initially involved a fusion of angiography and ventriculography within the Talairach atlas. ${ }^{10}$ Ventriculography was replaced with $\mathrm{CT}$ and MRI for co-registration as those techniques became available, allowing for improved visualization and planning. ${ }^{11}$

SEEG offered several potential advantages over SDE for certain types of intracranial investigations. While SDE allowed for excellent localization on the cortical surface, SEEG facilitated direct recording from virtually every cerebral structure and three-dimensional seizure localization. SEEG also offered a less invasive option for sampling disparate brain areas, bilateral investigations, and deep cortical areas. ${ }^{12}$

Despite over a half century of routine SEEG use in France and Italy, adoption of this technique in other parts of the world was limited until recently. This may be in part because SEEG yields less standardized and lower density sampling of the cortical surface than grids and strips or the lack of familiarity of many centers in localizing seizures based on this type of data. The procedure itself required manual adjustment of stereotactic coordinates for each electrode making it technically tedious and timeconsuming, and the need for cerebral angiography to avoid cerebral vasculature added additional time and risk. $^{13,14}$

It has only been in the last decade, with the application of stereotactic robotic assistance and demonstration of safety without the need for catheter-based angiography, that SEEG has seen wider adoption and greater familiarity with the data that it produces. ${ }^{15}$ Robotic stereotactic platforms allow operators to quickly navigate from one trajectory to the next with a high degree of accuracy and reliability. By reducing the manual burden on the surgeon and the time to set trajectories, robotics also opened the door to placing greater numbers of electrodes in more complex arrays. ${ }^{16}$ At the same time, early adopters demonstrated that they could avoid blood vessel injury and hemorrhage without the need for invasive angiography. The combination of high-volume gadolinium-enhanced T1-weighted MRI, and software that allows the surgeon to visualize and manipulate trajectories and anatomy in three-dimensional space, has likely contributed to the safe transition away from angiography. ${ }^{17}$ Mounting data on safety and utility, ${ }^{12,18}$ including experience specifically in the pediatric population where a less invasive approach may be particularly appealing, ${ }^{19-21}$ have supported further acceptance and more widespread adoption.

\section{Pre-implantation hypothesis, stereotactic planning, and surgical technique}

The goal of invasive monitoring is to localize the EZ and, in some cases, map adjacent or overlapping eloquent cortex. In most centers, a multidisciplinary team including neurosurgeons, epileptologists, and neuropsychologists will review the seizure semiology, neuropsychological testing, noninvasive EEG, and imaging modalities including structural MRI and, variably, positron emission tomography (PET), magnetoencephalography (MEG), functional MRI, and tractography, as well as a Wada test when warranted. Based on the level of confidence in the seizure onset zone, the vicinity to eloquent cortex, and the patient's preferences, invasive 
monitoring may be pursued. Available data are used to form a pre-implantation hypothesis and the choice of invasive monitoring technique and electrode coverage is based on this hypothesis, alternative hypotheses, and the vicinity to eloquent cortex. The pre-implantation hypothesis is critical because if it is incorrect, seizure recordings are unlikely to adequately define the EZ.

The choice of preoperative and intraoperative imaging has evolved over time and varies between centers. We obtain preoperative volumetric $(0.5 \mathrm{~mm}$ thin slice $) \mathrm{CT}$ and MRI with T1 gadolinium contrast-enhanced and T2 sequences. Some centers advocate for preoperative CT angiogram with iodinated contrast or catheter-based angiography to better visualize and avoid vasculature, though reported rates of hemorrhage are similarly low without additional vasculature imaging modalities (see Safety section below).

We perform all SEEG procedures with the ROSA robotic assistant device (Medtech, Montpellier, France) (Figure 1). All preoperative imaging can be loaded and merged in the ROSA Brain stereotactic planning software. Other options include the Cosman-Robert-Wells (CRW) (Integra LifeSciences, Plainsboro, NJ, USA) or Leksell (Elekta, Stockholm, Sweden) headframe systems in combination with any compatible stereotactic planning software or frameless stereotactic systems such as the VarioGuide (BrainLab, Munich, Germany) and StealthStation Vertek (Medtronic,
Minneapolis, Minnesota, USA), though these systems all require manual navigation to each stereotactic trajectory. Use of 3D-printed single-path, multiple trajectory systems, such as the FHC microTargeting Multi-Oblique Platform (FHC Inc., Bowdoin, ME, USA), obviate the need to navigate to each trajectory but limit the ability to adjust or add trajectories intra-operatively or add additional electrodes on short notice post-implantation. ${ }^{22,23}$ Robotic SEEG has been shown to reduce surgical time while maintaining safety and accuracy comparable to traditional methods. ${ }^{17,24}$ There is also experience using the Neuromate (RENISHAW, Gloucestershire, United Kingdom) stereotactic robot. ${ }^{25}$ The National Hospital for Neurosurgery and Neurology (NHNN) has developed the EpiNav system, which includes a proprietary stereotactic planning software and a robot micro-guide system that is integrated with the Medtronic StealthStation frameless neuronavigation system. ${ }^{26,27}$

Trajectories are planned based on the pre-implantation hypothesis of the seizure onset zone. Where feasible, we prefer trajectories that are nearly orthogonal to the skull as more oblique trajectories may be associated with greater inaccuracy. ${ }^{22,28,29}$ We avoid surface vessels based on preoperative imaging and minimize crossing sulci to reduce the risk of encountering the contained vasculature. Some common trajectories pass through the temporal neocortex superficially near the entry and reach the amygdala and hippocampal head, body, and tail at the target depth.
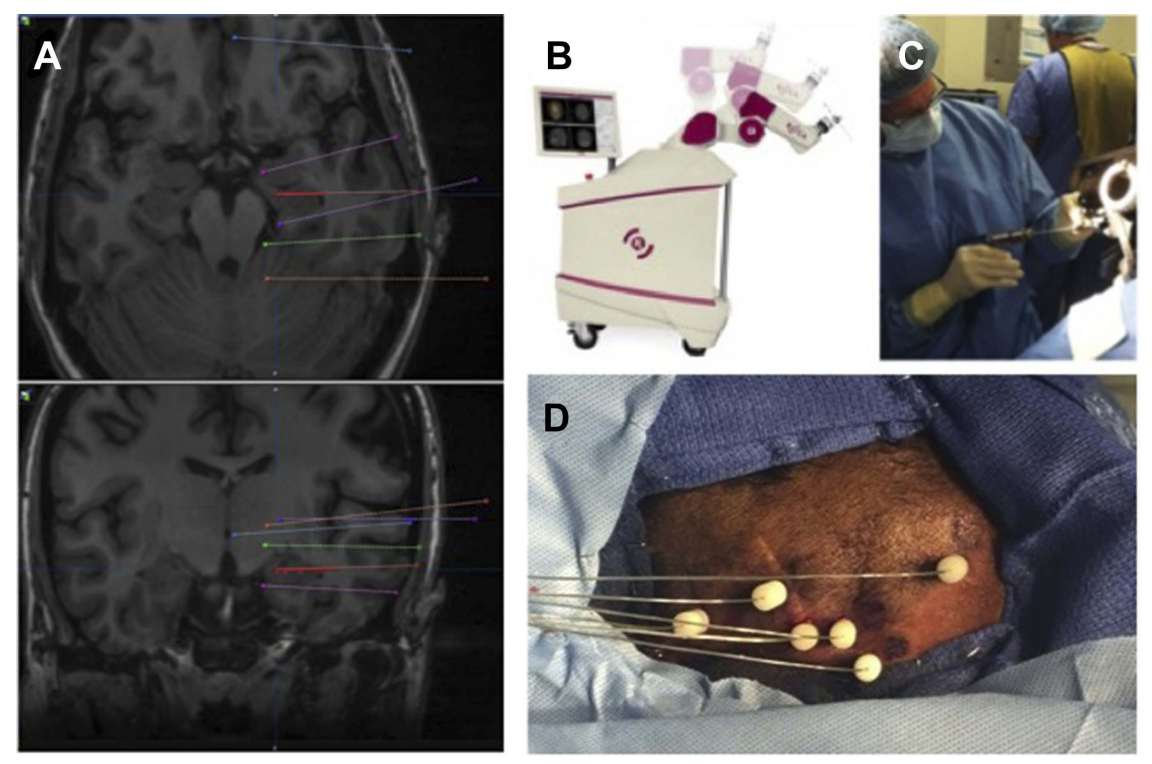

Figure I SEEG stereotactic planning and surgical technique. (A) Electrode trajectories are planned based on the pre-implantation hypothesis of the epileptogenic zone. We attempt to employ primarily orthogonal trajectories, avoid cortical vessels and sulci, and maximize gray matter sampling from gyral crowns, through sulcal cortex and depth of sulci, and to deep and medial targets. (B) After positioning and registration, the ROSA stereotactic robot is used to navigate to each trajectory in the operating room. (C) A small percutaneous incision and twist drill hole is made in line with the planned trajectory. (D) An anchor bolt is secured in the skull and the electrode passed to its premeasured depth and secured in the bolt. The process is repeated for each planned trajectory. 
Others pass through the frontal, parietal, and occipital neocortex and end in different areas of the cingulate gyrus medially. We will often take more oblique trajectories to sample in line with the transverse orientation of Heschl's gyrus or to pass from the frontal or parietal cortex to the insula while avoiding vasculature on the insula and opercular surface and in the Sylvian fissure. In addition to sampling from gyral crowns, we often place multiple electrode leads in the cortex adjacent to sulci and at their depth. The NHNN has also developed automated multiple trajectory planning integrated with the EpiNav system which can reduce planning time while reliably avoiding certain structures or angles as prescribed by the surgeon. ${ }^{30}$

On the day of surgery, patients are induced under general endotracheal anesthesia, fixed in a CRW headframe or other cranial fixation device, and registered using laser-based facial recognition. Some centers obtain an intraoperative CT scan after cranial fixation and others use skull fiducials for registration, usually in select cases where positioning may preclude facial registration. The robotic arm is positioned for each trajectory and a guide sleeve fixed in its platform. A twist drill hole is made using a 2.4-mm diameter drill (Stryker Medical, Kalamazoo, MI, USA). The dura is cauterized and opened with insulated coagulation probes and monopolar cautery, and an anchor bolt (PMT Corporation, Chanhassen, MN, USA) is secured in the drill hole. A $0.8-\mathrm{mm}$ diameter blunt, rigid stylet is then passed through the parenchyma to create a tract, and finally an electrode (PMT Corporation, 0.8-mm diameter, 5-mm contact space), with a pre-specified number of contacts and premeasured depth based on the planned trajectory, is inserted and secured. Other manufacturers of depth electrodes and placement systems include DIXI Medical (DIXI Medical, Chaudefontaine, Marne, France) and Ad-Tech Medical Instrument Corporation (Oak Creek, WI, USA). The procedure is repeated for each trajectory. We then obtain a brief sample of electrocorticography from each electrode in the operating room to confirm that they are functioning appropriately. Electrode positions can be confirmed with intraoperative volumetric CT scan, if available, or intraoperative skull X-ray followed by postoperative CT scan, as an alternative.

Patients then undergo continuous video monitoring and electrographic recording in the epilepsy monitoring unit (EMU). Antiepileptic medications are weaned and seizure provocation techniques employed as needed. Ictal and inter-ictal findings are discussed at interdisciplinary case conference. Electrode stimulation is used for mapping of various brain functions and for determination of which electrodes, when stimulated, recapitulate the patient's seizure semiology. Interpretation must take into account the three-dimensional aspect of depth electrode recordings and variable distances between contacts on different electrodes (Figure 2). Localization requires experience and an interpolation process including analysis of frequencies, spatial relations, and latencies.

\section{Safety}

Concerns regarding safety of SEEG likely contributed to its slow initial adoption. The most serious concern is the potential for numerous electrodes passed without direct visualization, through the skull and dura, deeply into the brain to cause intracranial hemorrhage. Early pioneers of SEEG relied on a combination of catheter-based angiography and stereotactic systems to avoid blood vessels. Two recent meta-analyses, predominantly based on experience with catheter-based angiography, found pooled prevalences for hemorrhage of $0.4^{11}$ and $1.0 \%{ }^{18}$ the latter study reported a rate of $0.4 \%{ }^{18}$ for intracranial bleeds requiring surgical evacuation. Intracerebral hemorrhage (ICH) was most prevalent but subdural and epidural bleeds occurred as well. More recently, multiple centers have eliminated catheter-based angiography, relying instead on high volume T1 gadolinium-enhanced MRI and/or CTA. These single-center series report similarly low rates of hemorrhage ranging from $0 \%$ to $1 \% .{ }^{17,31}$ Differences in hemorrhage rates between studies may be due, at least in part, to the lack of standardized reporting. More recently, in a single-center series of 549 SEEG implantations, McGovern, et al report a $19.1 \%$ rate of any hemorrhage when reviewing routine postoperative CT scans specifically for this purpose. ${ }^{32}$ More consistent with other reports, only $2.2 \%$ had symptomatic hemorrhage, $0.4 \%$ permanent deficit, and $0.2 \%$ ( 1 case) death. Notably, as their technique has evolved over time, there was no difference in hemorrhage rate between procedures performed with angiography, CTA, or MRI or with robotic versus frame-based stereotaxy. By comparison, a meta-analysis of SDE hemorrhages found most to be subdural and epidural with a pooled prevalence $4.0 \%$ overall and a $3.5 \%$ rate of hemorrhage requiring surgical evacuation. ${ }^{33}$ In a more recent, single-center experience comparing $139 \mathrm{SDE}$ and 121 SEEG cases, Tandon, et al reported 7 symptomatic hemorrhages in the SDE group and none in the SEEG cohort. ${ }^{34}$ Given the widespread use of advanced imaging 

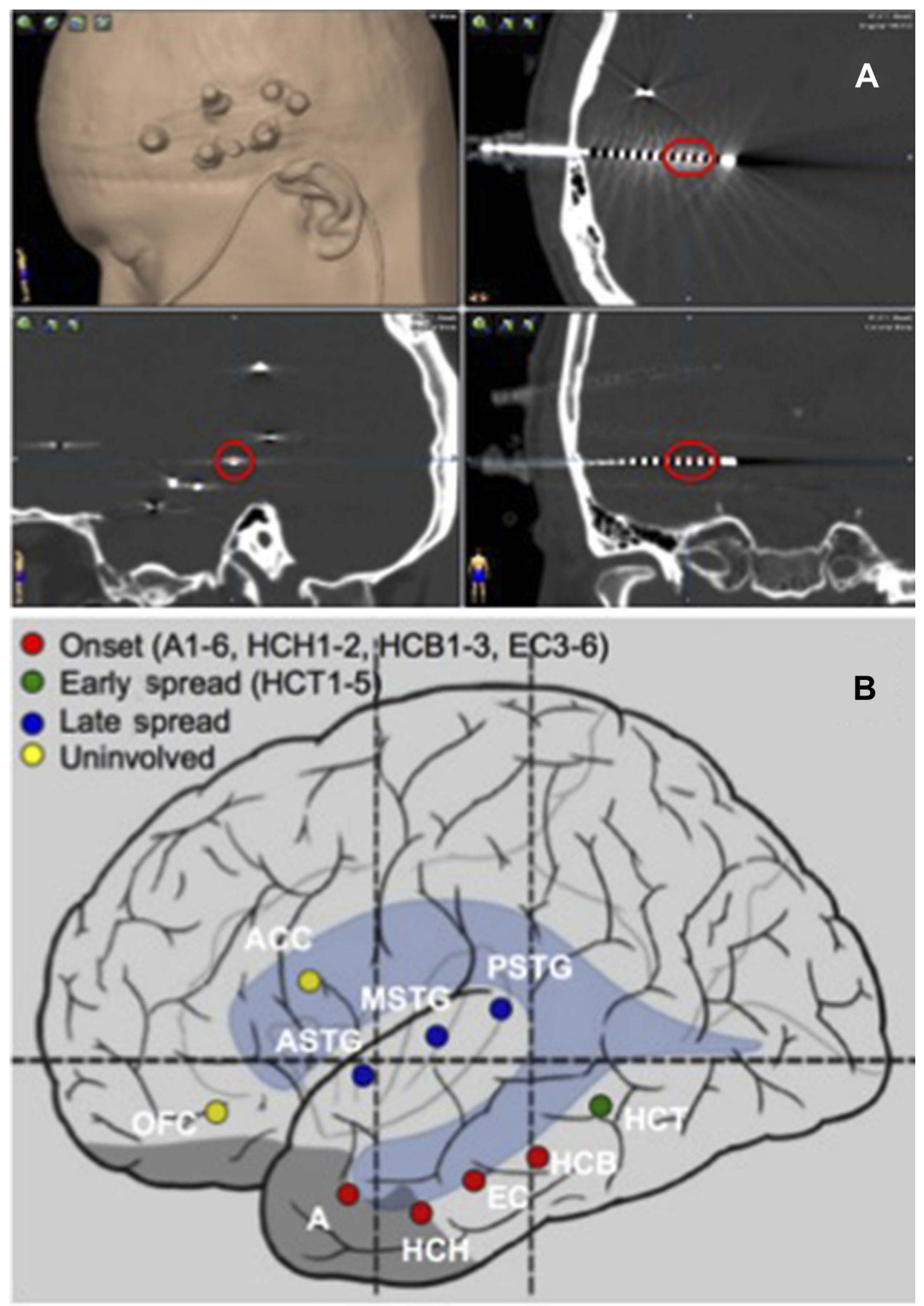

Figure 2 Localization of the epileptogenic zone. (A) A postoperative volumetric CT scan is obtained and used to localize each electrode contact in stereotactic space on the co-registered preoperative MRI. For each seizure recorded, the contacts involved are identified. (B) A summary of the contacts associated with seizure onset, early spread, and late spread is determined at an interdisciplinary epilepsy conference and used to plan further surgical intervention. Nomenclature is by convention. Each trajectory is named during the planning phase and numbers reflect the electrode contacts in order from deep to superficial (eg, $\mathrm{Al}-6=\mathrm{amygdala}$ electrode contacts $\mathrm{I}-6$; $\mathrm{HCHI}-2=$ hippocampal head electrode contacts $\mathrm{I}-2$ ).

and stereotactic guidance systems, it is reasonable to expect that the low rates of hemorrhage from SEEG can be maintained or improved over time.

Infection is the second most common complication with SEEG. The meta-analysis by Mullin et al reported a pooled prevalence of $0.8 \%$. By comparison, infection rates with SDE are likely over $5 \% .{ }^{35}$ The matched comparison by Tandon et al reported 3 infections in the SDE cohort and none in the SEEG group. ${ }^{34}$ Furthermore, SEEG electrodes are implanted through small percutaneous incisions and twist drill holes in the skull. Most infections are resolved with antibiotics and/or superficial debridement without surgical intervention. SDE infections often demand surgical evacuation and debridement and, in some cases, discarding the craniotomy bone flap followed by additional surgery for synthetic cranioplasty implantation after the infection has cleared. ${ }^{33}$

In the Mullin et al meta-analysis, hardware malfunctions, including broken electrodes and issues with recording, occurred at a rate of $0.4 \%$ with SEEG. ${ }^{18}$ By comparison, the SDE malfunction rate is approximately $1.3 \%{ }^{33}$ Other rare, reported complications include infarct, 
cerebral edema, photopsia, and reversible amnesia. ${ }^{18}$ Additional issues may arise during the monitoring period including deep vein thrombi, pulmonary emboli, urinary tract infections, psychiatric alterations, and allergic reactions. ${ }^{18}$ Altogether, SEEG's complications combined for a pooled prevalence of $1.3 \%$, with 5 reported deaths in 2,624 cases (pooled prevalence $0.3 \%$ ). ${ }^{18}$

While the above findings stem from mixed-age studies, one meta-analysis of specifically pediatric patients found similarly favorable results. ${ }^{20}$ After SEEG, $2.9 \%$ of the pediatric patients suffered from $\mathrm{ICH}$ and no patients were reported to have infectious complications. By comparison, SDE led to $\mathrm{ICH}$ in $10.7 \%$ of the pediatric patients and infection in another $10.8 \%$. The total complications rate with SEEG was $2.9 \%$ compared to $10.7 \%$ with SDE. More recent series of predominantly robot-assisted and MRI-based SEEG demonstrate similarly favorable results. $^{19,21}$

\section{Efficacy and utility in epilepsy}

The efficacy of SEEG can be difficult to assess. The accuracy of SEEG in localizing the EZ will depend primarily on the accuracy of the preimplantation hypothesis, as well as the adequacy of electrode coverage and interpretation of the recordings and any stimulation testing. Different centers and patients may have varying criteria and thresholds for when they will pursue an implant and when the findings are believed to justify surgical treatment. Finally, outcomes from any treatment interventions that follow will depend heavily on the focality and operability of the underlying epilepsies chosen for investigation and the options and choice of surgical treatment technique.

Efficacy can be approximated, in part, by the percentage of patients who go on to have definitive surgery aimed at resection or ablation of the seizure focus and the rates of seizure freedom in those patients. However, it should be kept in mind that identifying an unresectable EZ due to involvement of eloquent cortex or confirming multifocal or nonfocal epilepsy does not constitute a failure of SEEG. In a recent meta-analysis of 33 studies including 2,959 patients who underwent SEEG, the EZ was identified in $92 \%$ of the patients, $72 \%$ were eligible for epilepsy surgery, and 33\% were seizure free after surgery. ${ }^{36}$ Of those who underwent surgery, $47 \%$ achieved seizure freedom. Table 1 displays select series in the literature reporting definitive surgery outcomes with greater than 50 patients.
Rates of conversion from invasive monitoring to surgical intervention may underestimate the utility of SEEG. Given the growing evidence and patient perception that SEEG is less invasive than SDE, SEEG may lower the threshold for who undergoes an intracranial investigation and thus expand the invasive monitoring surgical population. This could inadvertently decrease the rate at which seizures are localized and patients undergo further treatment. In the single-center series by Tandon et al, SEEG was applied to a wider range of scenarios than SDE, including more nonlesional and bilateral cases. Perhaps as a result, SEEG cases were less likely to result in resection or ablation than SDE cases $(74.4 \%$ vs $91.4 \% ; p<0.001)$. However, favorable outcomes were observed in $76.0 \%$ of the SEEG cases compared to $54.6 \%$ of the SDE cases, suggesting the localization achieved with SEEG may be more definitive. ${ }^{34}$ In addition, SEEG affords the opportunity to delay further surgical discussions and interventions indefinitely after explant in the outpatient setting. By comparison, surgical removal of SDE usually requires reopening the surgical site and so resections are typically performed concurrently. While this change in practice is potentially beneficial for informed decision-making, it may also lead to more patients being lost to follow-up or choosing to forego a craniotomy when it is recommended. These factors could also bias SEEG towards lower rates of conversion from invasive monitoring to surgical treatment.

SEEG avoids unnecessary craniotomies and the associated morbidity, hospital stay, and costs. By contrast, subdural grids commit patients to at least two craniotomies: one for placement and one for removal. After sufficient SEEG data have been collected, percutaneous electrodes can be easily removed and patients discharged the same day. The clinical team can then further analyze the data and discuss treatment options with the patient and family, without prolonging the implant time and adding to the risk of infection. If seizure onsets are non-focal or multi-focal and no targeted surgical intervention is indicated, the patient has at least been spared an unnecessary craniotomy. For other patients, the appropriate first-line treatment may be another stereotactic procedure such as laser interstitial therapy (LITT), radiofrequency thermocoagulation (RF-TC), responsive neurostimulation (RNS), or deep brain stimulation (DBS), rather than an open resection, also sparing such patients a craniotomy. 


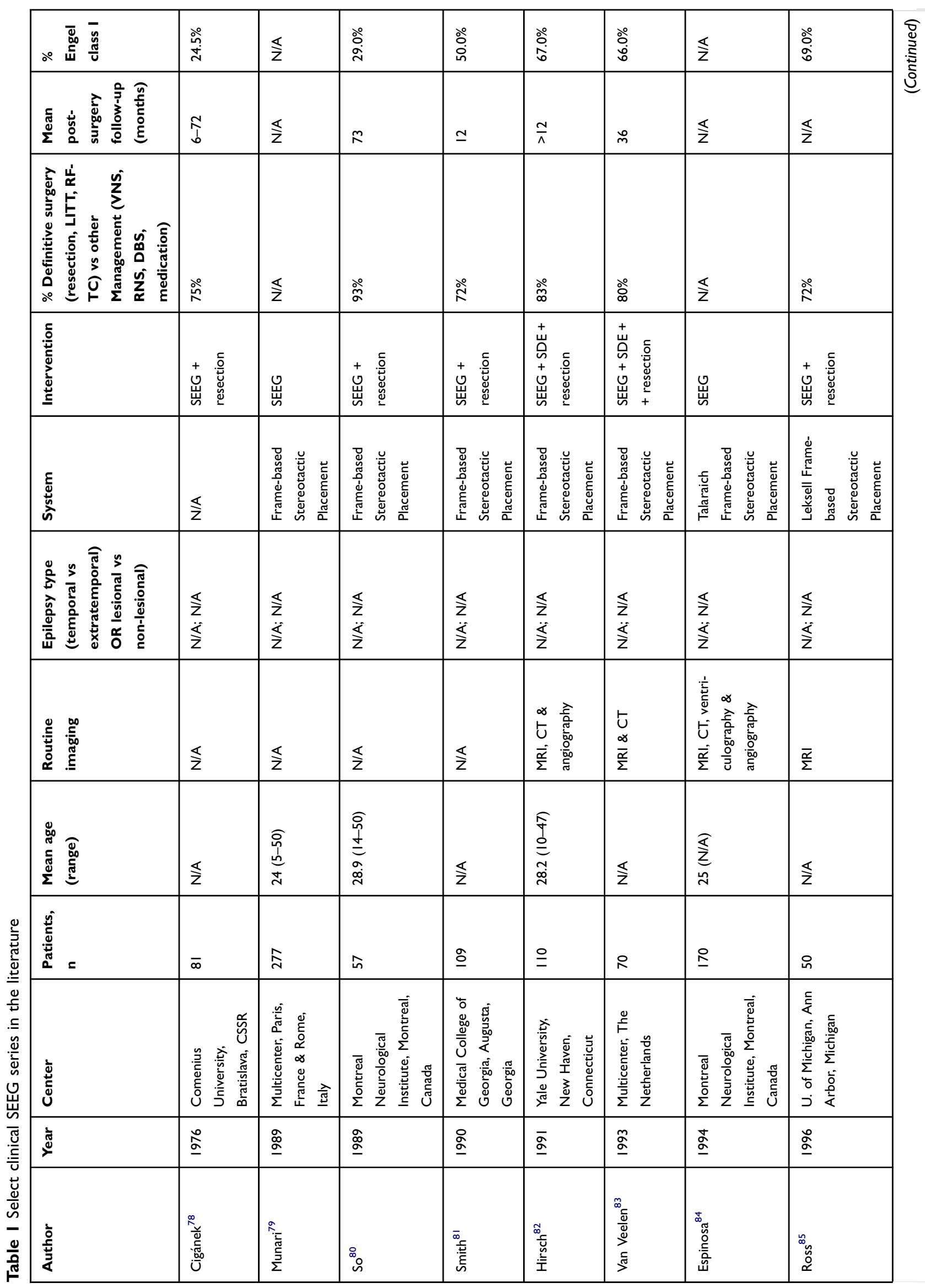




\begin{tabular}{|c|c|c|c|c|c|c|}
\hline 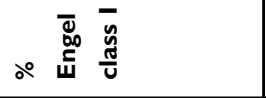 & $\overleftarrow{\Sigma}$ & $\begin{array}{l}\stackrel{\circ}{7} \\
\text { ஸे }\end{array}$ & 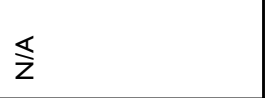 & $\stackrel{\circ}{\stackrel{\rho}{n}}$ & @ั̀ें & $\stackrel{\$}{z}$ \\
\hline 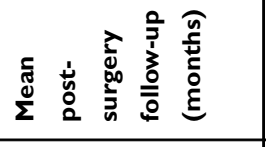 & $\overleftarrow{\Sigma}$ & $\simeq$ & 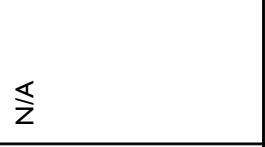 & $\stackrel{+}{m}$ & $\underline{n}$ & $\frac{\sim}{\wedge}$ \\
\hline 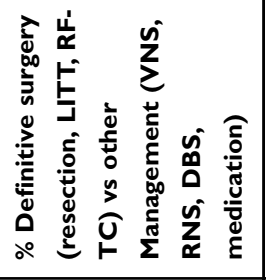 & 产 & $\stackrel{\circ}{\stackrel{\infty}{\infty}}$ & $\overleftarrow{z}$ & ○े & ํํㅅ & œे \\
\hline 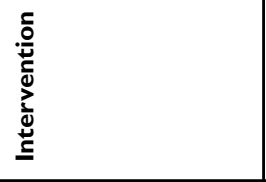 & 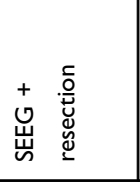 & 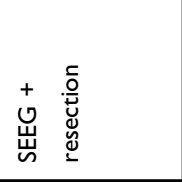 & 咄 & 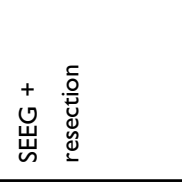 & 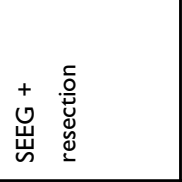 & 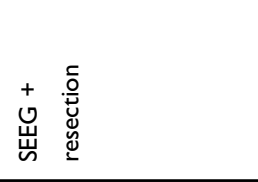 \\
\hline 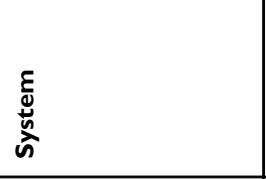 & 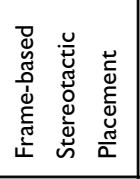 & 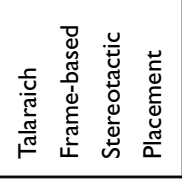 & 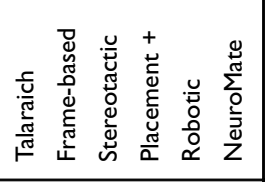 & 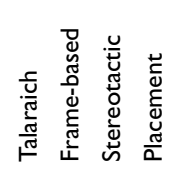 & 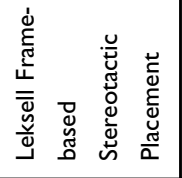 & 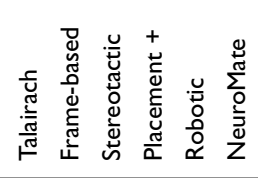 \\
\hline 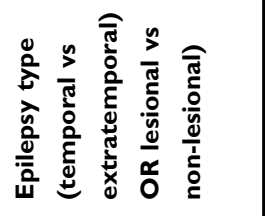 & & 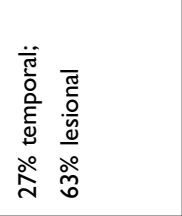 & 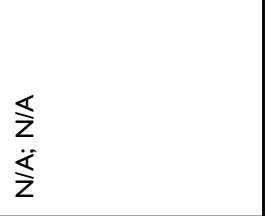 & 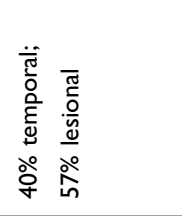 & $\begin{array}{l}\frac{X}{Z} \\
\dot{X} \\
z\end{array}$ & 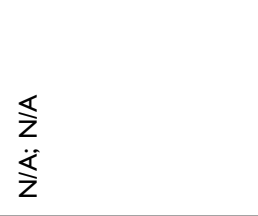 \\
\hline 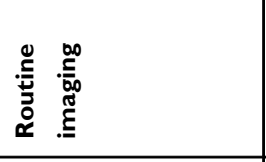 & 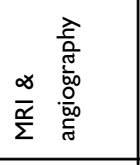 & 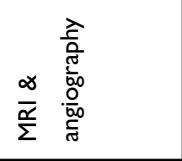 & 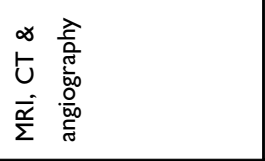 & $\begin{array}{l}\longleftarrow \\
\propto \\
\bar{\alpha} \\
\bar{\alpha}\end{array}$ & 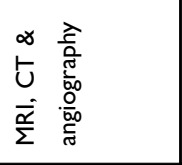 & 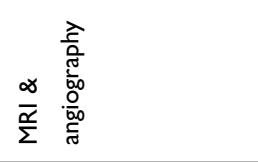 \\
\hline 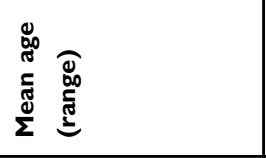 & 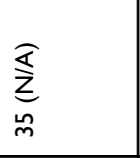 & 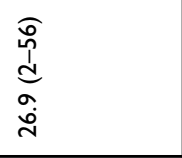 & 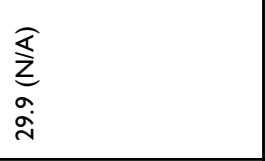 & $\begin{array}{l}\widehat{o} \\
\infty \\
\infty \\
0 \\
\infty \\
\sim\end{array}$ & 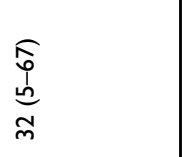 & $\begin{array}{l}\widehat{D} \\
\stackrel{0}{d} \\
\frac{\pi}{z}\end{array}$ \\
\hline 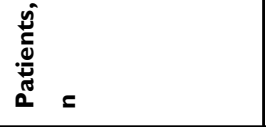 & 음 & $\overline{\bar{N}}$ & $\overline{\mathrm{N}}$ & 음 & 음 & $\underset{\text { w }}{\tilde{W}}$ \\
\hline 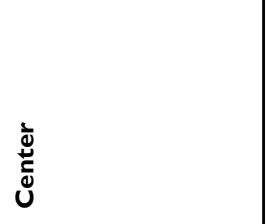 & 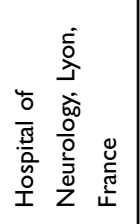 & 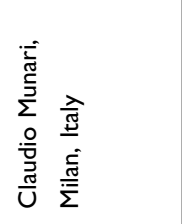 & 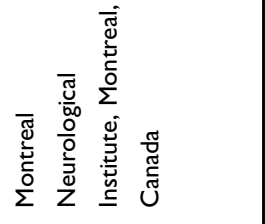 & 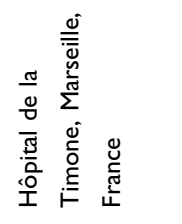 & 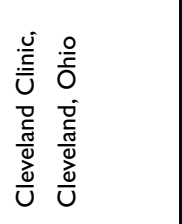 & 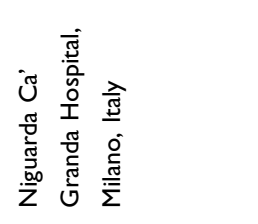 \\
\hline ટ્ & $\overline{\mathrm{d}}$ & ํㅗㅇ & ঃั & ڤ્ণે & $\frac{m}{i}$ & $\frac{m}{i}$ \\
\hline & 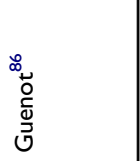 & 嗙 & 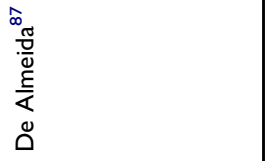 & 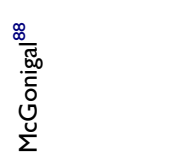 & 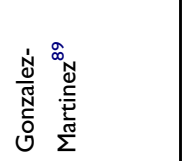 & 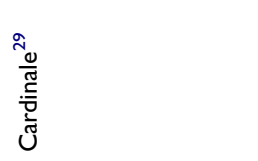 \\
\hline
\end{tabular}




\begin{tabular}{|c|c|c|c|c|c|c|}
\hline 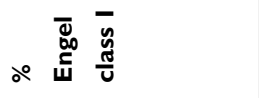 & $\stackrel{\circ}{\stackrel{\circ}{\infty}}$ & خั่ & $\begin{array}{l}\stackrel{\circ}{0} \\
\stackrel{\circ}{\circ}\end{array}$ & $\begin{array}{l}\stackrel{\circ}{\circ} \\
\underline{\infty}\end{array}$ & 今ั & $\begin{array}{l}\stackrel{\circ}{\circ} \\
\infty\end{array}$ \\
\hline 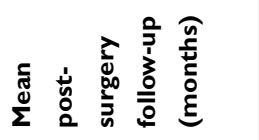 & 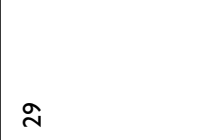 & $\simeq$ & $\stackrel{ \pm}{\sim}$ & $\widehat{\nwarrow}$ & $\underline{\infty}$ & $\approx$ \\
\hline 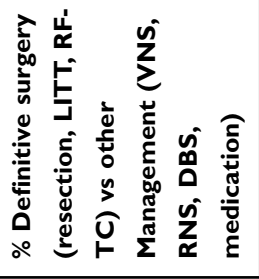 & ㅇํㅇ & $\stackrel{\circ}{\stackrel{\circ}{N}}$ & $\stackrel{\circ}{\stackrel{\circ}{\triangleright}}$ & ○̊ & ळ̊ & ڤ̊ํํ \\
\hline 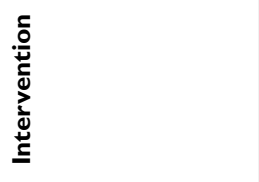 & 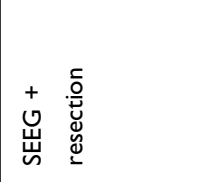 & 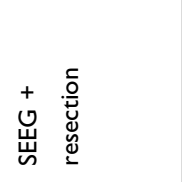 & 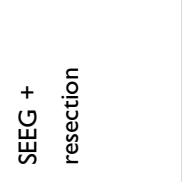 & 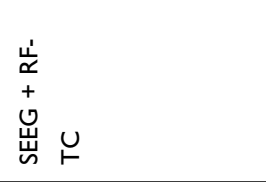 & 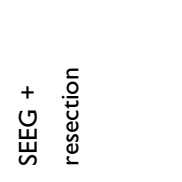 & 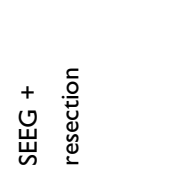 \\
\hline $\begin{array}{l}\frac{\varepsilon}{\Phi} \\
\text { जे } \\
\text { nे }\end{array}$ & 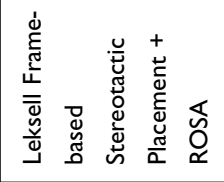 & 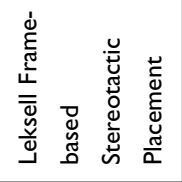 & 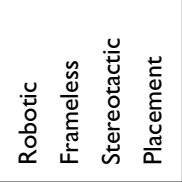 & 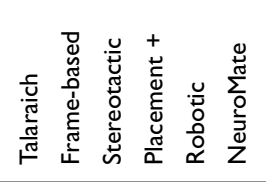 & 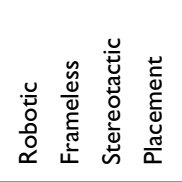 & 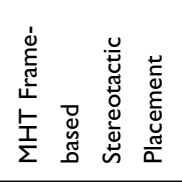 \\
\hline 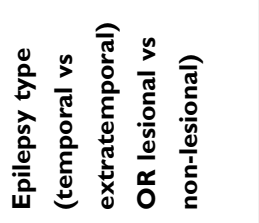 & 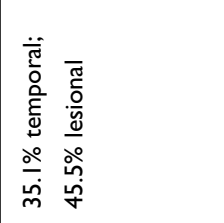 & 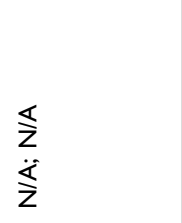 & 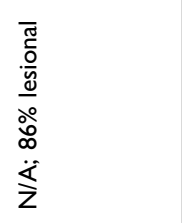 & 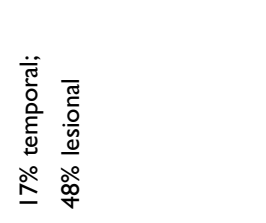 & 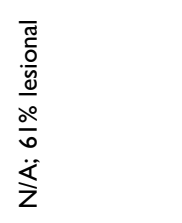 & 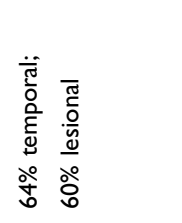 \\
\hline 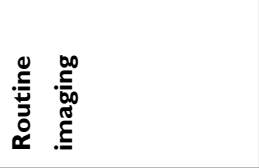 & 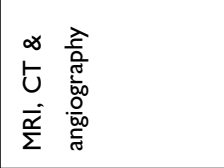 & 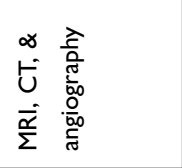 & $\overline{\underline{\Sigma}}$ & 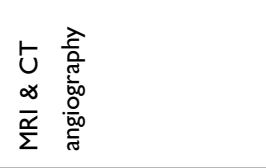 & $\overline{\underline{\alpha}}$ & 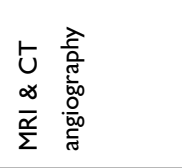 \\
\hline 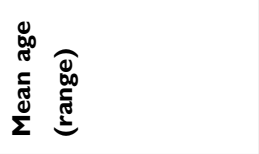 & $\begin{array}{l}\text { âd } \\
\text { c } \\
\text { c } \\
\text { m }\end{array}$ & $\begin{array}{l}\text { ô } \\
\text { i } \\
0 \\
0 \\
0 . j \\
m\end{array}$ & $\underset{\substack{N \\
\infty}}{\substack{1 \\
\infty}}$ & 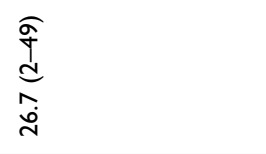 & $\begin{array}{l}\text { f } \\
i \\
0 \\
N \\
m \\
m\end{array}$ & 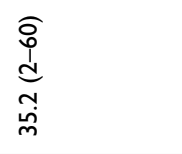 \\
\hline 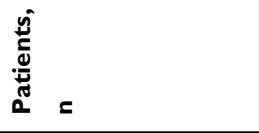 & ঃ্ণ & $\cong$ & ถి & ळి & $\underline{8}$ & $\stackrel{\leftrightarrow}{\infty}$ \\
\hline 仓ั๊ & 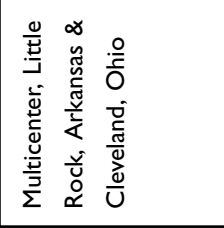 & 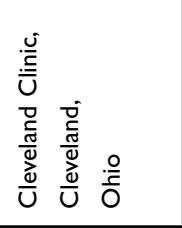 & 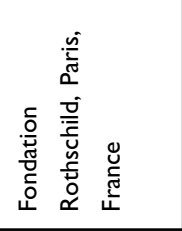 & 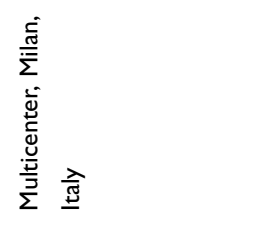 & 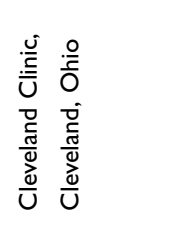 & 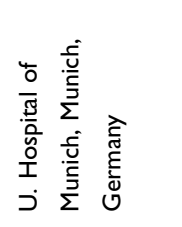 \\
\hline$\stackrel{\text { હँ }}{\nu}$ & $\stackrel{+}{\circ}$ & $\stackrel{+}{\frac{\pi}{a}}$ & $\stackrel{+}{\circ}$ & $\stackrel{n}{\frac{n}{d}}$ & $\stackrel{\circ}{\circ}$ & $\frac{\circ}{\bar{N}}$ \\
\hline 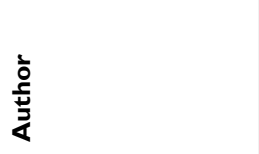 & 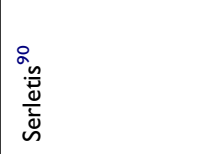 & 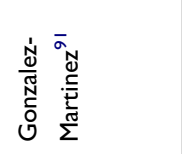 & 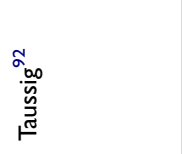 & 梁 & 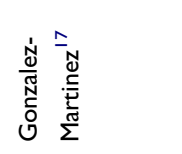 & 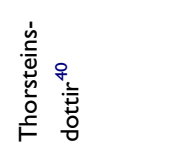 \\
\hline
\end{tabular}


While SEEG has several potential advantages over $\mathrm{SDE}$, grids and strips may be preferable for certain situations both as the first line for invasive monitoring and after SEEG. Grids provide a higher density, more standardized two-dimensional map of the outer brain surface, which may be preferable for localizing a unilateral superficial neocortical focus. When seizure onsets are near or involving eloquent cortex, a standardized two-dimensional grid can also be used for more detailed extraoperative functional mapping, particularly in or near language cortex. In certain cases, it may be appropriate to pursue SDE after SEEG, such as when SEEG has confirmed a cortical onset but the boundaries of the seizure onset zone and eloquent cortex remain unclear.

\section{Specific applications of SEEG}

SEEG may be particularly beneficial for certain types of intracranial investigations where it would be impractical or challenging to achieve similar coverage with SDE. SEEG allows for relatively easy sampling from deep and medial structures, gray matter in the depths of sulci, circumspherically around deep lesions and prior resection or ablation sites, and simultaneously from multiple lobes or bilateral hemispheres. Vadera et al reported on 14 patients who underwent SEEG after SDE failed to localize the EZ. ${ }^{37}$ Of the 14,10 went on to SEEG-guided resections. Of these 10, 7 involved deeply seated neocortical foci and 6 patients ultimately achieved Engel class I outcomes.

\section{Bilateral investigations}

SEEG provides utility in cases where the laterality of seizure onsets is unclear. This is particularly useful in cases of deep or mesial epilepsies where rapid spread to the contralateral hemisphere makes lateralization with scalp EEG challenging. Bilateral grids would significantly increase invasiveness and morbidity and may not offer significant advantage over scalp EEG for such medial onsets. However, the likelihood of seizure freedom may be relatively low in this group. In a single-center series, 106 (58\%) of 184 patients who underwent bilateral SEEG investigations underwent resection. ${ }^{38}$ Only 26 (32\%) of 81 patients with greater than 1-year follow-up achieved seizure freedom. Notably, SEEG confirmed that $48 \%$ of the patients had multiple seizure foci and $40 \%$ had bilateral independent onset zones.

\section{Temporal lobe epilepsy}

SEEG is frequently used in investigations of suspected temporal lobe epilepsy. With proper planning, electrodes can simultaneously sample the temporal neocortex, including deep sulcal gray matter, and mesial structures like the amygdala and hippocampus, with high degree of accuracy. Such investigations commonly sample from the basal temporal lobe, frontal operculum and basal frontal lobe, the insular cortex, and cingulate gyrus, and can be tailored to include additional frontal, parietal, or occipital coverage as indicated. Multiple studies have reported high rates of seizure freedom following SEEG localization to the temporal lobe, ranging from $72.7 \%$ to $80 \% .{ }^{17,39,40}$ SEEG can be particularly useful in cases where the laterality of suspected mesial temporal onset is unclear and in cases of mesial temporal lobe epilepsy (MTLE) without mesial temporal sclerosis. Seizure onsets localized to the amygdalohippocampus $(\mathrm{AH})$ may be treated with a more tailored selective laser amygdalohippocampotomy $(\mathrm{SLAH})^{41,42}$ or open selective amygdalohippocampectomy $(\mathrm{SAH})^{43,44}$ rather than anterior temporal lobectomy, which includes resection of the temporal neocortex and is associated with greater neurocognitive side effects. Some series suggest that patients without MTS (ie, non-lesional MTLE) may respond as well to $\mathrm{SLAH}^{41}$ or $\mathrm{SAH}^{44}$ as those with MTS if seizure onset can be localized to the AH with SEEG.

\section{Extra-temporal epilepsy}

SEEG has shown efficacy in extra-temporal epilepsy, including both nonlesional cases and lesional cases with discordant noninvasive workups. Seizure freedom following surgery for extra-temporal lobe epilepsy localized with SEEG range from $50 \%$ to $84 \% .{ }^{17,39,40}$ Early experience suggests SEEG can also guide extra-temporal laser ablation. ${ }^{45,46}$ In one series, 4 pediatric patients ( 2 with tuberous sclerosis and 2 with focal cortical dysplasia) underwent SEEG followed by LITT. ${ }^{46}$ At mean followup of 9.3 months, 3 patients were seizure free and 1 had significant improvement. In another series, 3 patients with nonlesional epilepsy underwent laser ablation targeting small $\left(<2 \mathrm{~cm}^{3}\right)$, difficult to access areas after SEEG identified the seizure onsets. ${ }^{45}$ The patient was seizure free at 20 months. SEEG can also inform a combined staged laser ablation and open resection strategy in complex malformations of cortical development. ${ }^{47}$

\section{Insular epilepsy}

SEEG may improve access to investigate the insular cortex, which is deep to the frontal, parietal, and temporal opercula, and covered by Sylvian and distal middle 
cerebral artery vessels. Some centers favor an oblique approach to the insula with entry points in the frontal or parietal convexity to avoid crossing the Sylvian fissure and vessels on the surface of the insula and operculum. Others favor orthogonal approaches that sample the operculum en route to the insula and provide a more standardized matrix of electrodes for interpretation. In one center's experience of 135 patients whose investigation included insular coverage with primarily orthogonal approaches, none experienced hemorrhagic complication. ${ }^{48}$ Notably, only 23 (17\%) were found to have insular onsets emphasizing the importance of also sampling the overlying opercula regardless of which trajectories are taken.

\section{Hypothalamic hamartoma}

SEEG may also have a role in the investigation of deepseated hypothalamic hamartomas ${ }^{49}$ particularly when there is extended epileptogenicity beyond the lesion. ${ }^{50}$ In one series of 9 patients who underwent SEEG-guided RF-TC, 5 patients experienced Engel class I outcomes and 4 were Engel II. ${ }^{51}$

\section{Periventricular nodular heterotopia (PVNH)}

Similarly, SEEG has enhanced the evaluation of PVNH. ${ }^{12}$ SEEG allows for concomitant exploration of the deep heterotopic nodules as well as associated or alternative potential foci in the mesial temporal lobe or overlying cortex. In a recent study, $17(85 \%)$ of 20 patients with epilepsy related to PVNH underwent SEEG-guided radiofrequency thermocoagulation, and 13 (76\%) experienced Engel class I outcomes. ${ }^{52}$ There have also been isolated case reports of SEEG-guided LITT to localize and ablate PVNH seizure foci in a subsequent procedure. ${ }^{53}$

\section{Prior epilepsy surgery}

Craniotomy and subdural grid placement may be especially morbid or challenging in patients who have undergone a prior craniotomy and resection due to scarring of the pia, arachnoid, and dura, whereas the approach and risks with SEEG are largely unchanged in this population. ${ }^{32}$ After prior craniotomy, SDE carries an increased incidence of hemorrhage, infection, and wound leak. ${ }^{54,55}$ Another concern revolves around the limitations induced by scar tissue; prior incisions and cortical adhesions constrain efficacy of the recordings. ${ }^{56}$ By comparison, the safety of SEEG is likely unchanged in patients with prior surgery. In two series, one with 14 patients in whom seizures were not localized after craniotomy for subdural grids, ${ }^{37}$ and another in which 14 patients did not achieve seizure freedom after resections, ${ }^{57}$ only 1 patient experienced a major complication, an abscess, with SEEG. In the former study, 10 of 14 patients went on to definitive surgery and 6 achieved seizure freedom. ${ }^{37}$ In the latter, 9 of 14 achieved seizure-free outcomes. ${ }^{57}$ Another series reported 21 of 29 reoperative cases achieving Engel class I outcomes after seizures were localized with SEEG; complications were not reported separately for the subgroup. ${ }^{12}$

\section{SEEG-guided radiofrequency thermocoagulation (RF-TC)}

In addition to guiding laser ablation, several centers have reported SEEG-guided RF-TC, as mentioned in the context of hypothalamic hamartoma and PVNH above. In this technique, thermocoagulation is performed via the SEEG contacts to create a focal lesion, potentially sparing the patient further stereotactic procedures. Seizure freedom appears to be lower than with laser ablation and open surgical technique, though there is limited experience and results are highly variable. A recent meta-analysis reported a pooled seizure freedom rate of $23 \%{ }^{58}$ Seizure freedom was highest among patients with heterotopias (38\%) and hippocampal sclerosis $(25 \%)$ and lower in FCD $(18 \%)$ and nonlesional epilepsy (11\%).

\section{Epileptogenic networks}

SEEG's capacity for bilateral and multi-lobar sampling allows for the evaluation of epileptogenic networks underlying seizure initiation and propagation. Electrocorticography has traditionally attempted to define a single seizure onset zone, but SEEG can further delineate more remote structures involved in amplification. ${ }^{59}$ Defining the epileptogenic network can guide the extent of an initial resection or ablation or inform the next hypothesis when a tissue destructive procedure fails. As options for neuromodulation continue to advance, SEEG may also guide a more informed approach to the targeted disruption of seizure propagation, particularly in cases of eloquent cortex, multifocal, and nonfocal epilepsy.

\section{Role in cognitive neurophysiology}

SEEG offers an opportunity to confirm and extend cognitive neuroscience research from other modalities. ${ }^{60}$ The 
ability to observe neurophysiological signals with high temporal and spatial resolution between precisely localizable populations of neurons across distinct brain regions can inform mechanistic understanding of perceptual and cognitive functions. In particular, high-frequency broadband oscillation, also known as high gamma oscillatory activity, is a reliable electrophysiologic correlate of underlying averaged spiking activity generated by thousands of neurons. ${ }^{61-64}$ High gamma also correlates with the hemodynamic signals in functional MRI. ${ }^{63,65,66}$ Several studies have also reported the use of combined electrodes that can record the local field potentials needed for clinical localization of the EZ and single unit neuronal activity, allowing for the study of response in isolated neurons to various stimuli or other study paradigms.

SEEG has several technical advantages over other modalities. Compared to noninvasive imaging modalities such as functional MRI, SEEG offers significantly greater temporal resolution. It also offers greater spatial resolution and greater signal-to-noise ratio than fMRI or scalp EEG, though the spatial coverage is limited to areas targeted based on the preimplantation hypothesis rather than the entire brain. Compared to subdural grids, the wide range of brain areas covered and three-dimensional arrays allow for the study of multiple nodes in a network and can provide information about functional interactions within and across networks. The orthogonal alignment of many SEEG electrodes allows one to examine the involvement of multiple layers of the cerebral cortex mantle. Indeed, the adoption of SEEG has seen with it a steady rise in the number of scientific publications related to intracranial EEG. $^{60}$

Direct electrical stimulation via SEEG electrodes (or other simultaneously implanted electrodes) offers the ability to record and stimulate the human brain at specific sites and test the causal importance of a given population of neurons and their interconnections for a particular function. SEEG also provides an opportunity to record and stimulate during uniquely human tasks or experiences while the subjective report of the human participant is immediately available. ${ }^{67}$

\section{Future directions in psychiatric disease}

The history of SEEG and psychiatric neurosurgery have long been intertwined. Talairach was a psychiatrist who later trained as a neurosurgeon. He developed stereotactic surgery for SEEG and epilepsy but also to treat psychiatric patients using stereotactic lesioning of subcortical regions. ${ }^{68}$ He was the first to describe anterior capsulotomy. ${ }^{68}$ The development of psychopharmacology between 1950 and 1960 and the overzealous application of psychosurgery in that time drove clinical research away from the field for decades. However, with the success and safety of deep brain stimulation, a relatively reversible procedure, for movement disorders and the persistence of medication refractory psychiatric diseases, there has been renewed interest in using stereotactic procedures and neuromodulation for psychiatric indications. ${ }^{69}$ Deep brain stimulation holds a humanitarian device exemption for obsessive-compulsive disorder (OCD) from the Food and Drug Administration (FDA) and has been investigated for diseases including depression, schizophrenia, post-traumatic stress disorder, addiction, selfinjurious behavior, anorexia nervosa, and obesity. ${ }^{70}$ Much of the justification for these studies has come from a growing understanding of network dysfunction in psychiatric disease and hypotheses that neurostimulation can modulate these networks in a therapeutic manner. Several authors have attributed the failure of some of these trials, at least in part, to inadequate targeting on the basis of symptom complexes and corresponding network dysfunction. ${ }^{71,72}$

SEEG's advantages in terms of spatial and temporal resolution in the study of normal human cognitive neurophysiology should theoretically apply to the study of network dysfunction in psychiatric disease as well. SEEG could therefore be used diagnostically to identify patterns of network dysfunction that justify a specific target for neurostimulation. In addition, SEEG has the added advantage that it can potentially be used concurrently with stimulation to measure the effects on network activity. In one ongoing study, investigators will concurrently place SEEG and DBS electrodes with directional steering, to understand symptomatic networks and engage those networks on an individualized basis. ${ }^{73}$ They will target the subgenual cingulate and ventral capsule/ventral striatum.

The availability of the Responsive Neurostimulation $\left(\mathrm{RNS}^{\circledR}\right)$ System NeuroPace (Mountain View, California, USA), a closed-loop stimulation system also developed for epilepsy, ${ }^{74}$ promises a more dynamic approach to neuromodulation for psychiatric disease. ${ }^{75}$ The RNS system consists of an implanted device that can detect neurophysiologic signals and respond to specific patterns in real time. One trial is underway using RNS for loss of control eating targeting biomarkers in the nucleus accumbens. ${ }^{76} \mathrm{In}$ another study, researchers will use a novel bidirectional 
neuromodulation system (Activa $\mathrm{RC}+\mathrm{S}$, Medtronic, Minneapolis, MN, USA) to measure local field potentials at the site of stimulation in the subgenual cingulate and define future parameters for close-loop stimulation. ${ }^{77}$

SEEG may have a future role in identifying the stereotactic targets and neurophysiologic biomarkers for stimulation and studying the effects of stimulation prior to, or concurrently with, system implantation. In this paradigm, an inpatient Psychiatric Monitoring Unit (PMU) will be developed, analogous to the Epilepsy Monitoring Unit (EMU) that is currently present in all academic epilepsy centers. Similar to an epilepsy patient multidisciplinary team case conference that occurs prior to any SEEG implant, a psychiatric patient's amalgamated clinical and neuroimaging data would undergo an intensive review as to potential candidacy for network modulation and optimal possible neuromodulatory targets. Following a SEEG implantation exploring these specific networks, the patient would return to the PMU for recording of brain activity from the implanted cortical and white matter targets, and for careful stimulation of these specific sites to assess biological effect. In this way, specific treatment of particular brain sites could be tested in the PMU for short-term efficacy, potentially improving the safety and success of a more permanent continuous or closed-loop neuromodulation system.

\section{Conclusion}

Bolstered by stereotactic robotic assistance and growing evidence of safety without catheter-based angiography, SEEG has gained wider acceptance as a first line intracranial monitoring approach for many pre-implantation hypotheses. Rates of clinically significant hemorrhage, infection, and other complications appear lower with SEEG than with SDE. The efficacy of SEEG as a diagnostic tool is difficult to assess as outcomes depend heavily on how and when it is employed, interpretation of the findings, and subsequent treatments. At a minimum, SEEG may spare patients craniotomies if no single, resectable $\mathrm{EZ}$ is identified or a stereotactic intervention such as LITT, RF-TC, RNS, or DBS is ultimately pursued. While SDE allows for excellent localization and functional mapping on the outer cortical surface, SEEG offers a less invasive option for many intracranial investigations where it would be impractical or challenging to achieve similar coverage with SDE. SEEG allows for relatively easy sampling from virtually anywhere in the brain including deep and medial structures, gray matter in the depths of sulci, circumspherically around deep lesions and prior resection or ablation sites, and simultaneously from multiple lobes or bilateral hemispheres. SEEG has been employed to investigate potential seizure onsets in the temporal lobe, the insula, lesional and non-lesional extratemporal epilepsy, hypothalamic hamartoma, periventricular nodular heterotopia, and when patients have had prior craniotomies. SEEG supports the investigation of seizures as an epileptogenic network rather than a single focus, which may have important implications for the study and treatment of epilepsy not currently amenable to focal treatment techniques. SEEG also offers a valuable opportunity for cognitive neurophysiology research and may have an important role in the study of dysfunctional networks in psychiatric disease and understanding the potential effects of neuromodulation.

\section{Disclosure}

The authors report no conflicts of interest in this work.

\section{References}

1. Brodie MJ, Barry SJ, Bamagous GA, Norrie JD, Kwan P. Patterns of treatment response in newly diagnosed epilepsy. Neurology. 2012;78 (20):1548-1554. doi:10.1212/WNL.0b013e3182563b19

2. Kwan P, Brodie MJ. Early identification of refractory epilepsy. $N$ Engl J Med. 2000;342(5):314-319. doi:10.1056/NEJM200002033 420503

3. Kwan P, Arzimanoglou A, Berg AT, et al. Definition of drug resistant epilepsy: consensus proposal by the ad hoc task force of the ILAE commission on therapeutic strategies. Epilepsia. 2010;51 (6):1069-1077. doi:10.1111/j.1528-1167.2009.02397.x

4. Englot DJ, Wang DD, Rolston JD, Shih TT, Chang EF. Rates and predictors of long-term seizure freedom after frontal lobe epilepsy surgery: a systematic review and meta-analysis. J Neurosurg. 2012;116(5):1042-1048. doi:10.3171/2012.1.JNS111620

5. Piotrowska N, Winkler PA. Otfrid Foerster, the great neurologist and neurosurgeon from Breslau (Wroclaw): his influence on early neurosurgeons and legacy to present-day neurosurgery. $J$ Neurosurg. 2007;107(2):451-456. doi:10.3171/JNS-07/08/0451

6. Penfield W, Jasper HH. Epilepsy and the Functional Anatomy of the Human Brain. 1st ed. Boston: Little; 1954.

7. Voorhies JM, Cohen-Gadol A. Techniques for placement of grid and strip electrodes for intracranial epilepsy surgery monitoring: pearls and pitfalls. Surg Neurol Int. 2013;4:98. doi:10.4103/2152-7806.115707

8. Gonzalez-Martinez JA. The stereo-electroencephalography: the epileptogenic zone. $J$ Clin Neurophysiol. 2016;33(6):522-529. doi:10.1097/WNP.0000000000000287

9. Iida K, Otsubo H. Stereoelectroencephalography: indication and efficacy. Neurol Med Chir (Tokyo). 2017;57(8):375-385. doi:10.2176/nmc.ra.2017-0008

10. Talairach J, Tournoux P. Co-Planar Stereotaxic Atlas of the Human Brain: An Approach to Medical Cerebral Imaging. Stuttgart, New York: G. Thieme; Thieme Medical Publishers; 1988.

11. Cardinale F, Casaceli G, Raneri F, Miller J, Lo Russo G. Implantation of Stereoelectroencephalography electrodes: a systematic review. J Clin Neurophysiol. 2016;33(6):490-502. doi:10.1097/WNP.0000000000000287

12. Podkorytova I, Hoes K, Lega B. Stereo-encephalography versus subdural electrodes for seizure localization. Neurosurg Clin $\mathrm{N} \mathrm{Am}$. 2016;27(1):97-109. doi:10.1016/j.nec.2015.11.005 
13. Scorza D, Amoroso G, Cortes C, et al. Experience-based SEEG planning: from retrospective data to automated electrode trajectories suggestions. Healthc Technol Lett. 2018;5(5):167-171. doi:10.1049/ htl.2018.5075

14. Musolino A, Tournoux P, Missir O, Talairach J. Methodology of "in vivo" anatomical study and stereo-electroencephalographic exploration in brain surgery for epilepsy. J Neuroradiol. 1990;17(2):67-102.

15. Goto T, Hongo K, Kakizawa Y, et al. Clinical application of robotic telemanipulation system in neurosurgery. Case report. J Neurosurg. 2003;99(6):1082-1084. doi:10.3171/jns.2003.99.6.1082

16. Sutherland GR, Maddahi Y, Gan LS, Lama S, Zareinia K. Robotics in the neurosurgical treatment of glioma. Surg Neurol Int. 2015;6(Suppl 1):S1-8. doi:10.4103/2152-7806.170024

17. Gonzalez-Martinez J, Bulacio J, Thompson S, et al. Technique, results, and complications related to robot-assisted stereoelectroencephalography. Neurosurgery. 2016;78(2):169-180. doi:10.1227/NEU.0000000000001034

18. Mullin JP, Shriver M, Alomar S, et al. Is SEEG safe? A systematic review and meta-analysis of stereo-electroencephalography-related complications. Epilepsia. 2016;57(3):386-401. doi:10.1111/epi.13298

19. McGovern RA, Knight EP, Gupta A, et al. Robot-assisted stereoelectroencephalography in children. J Neurosurg Pediatr. 2018;23 (3):288-296. doi:10.3171/2018.7.PEDS18305

20. Sacino MF, Huang SS, Schreiber J, Gaillard WD, Oluigbo CO. Is the use of stereotactic electroencephalography safe and effective in children? A meta-analysis of the use of stereotactic electroencephalography in comparison to subdural grids for invasive epilepsy monitoring in pediatric subjects. Neurosurgery. 2019;84(6):1190-1200. doi:10.1093/neuros/nyy466

21. Goldstein HE, Youngerman BE, Shao B, et al. Safety and efficacy of stereoelectroencephalography in pediatric focal epilepsy: a single-center experience. J Neurosurg Pediatr. 2018;22(4):444-452. doi:10.3171/2018.5.PEDS1856

22. Dewan MC, Shults R, Hale AT, et al. Stereotactic EEG via multiple single-path omnidirectional trajectories within a single platform: institutional experience with a novel technique. $J$ Neurosurg. 2018;129(5):1173-1181. doi:10.3171/2017.6.JNS17881

23. Yu H, Pistol C, Franklin R, Barborica A. Clinical accuracy of customized stereotactic fixtures for stereoelectroencephalography. World Neurosurg. 2018;109:82-88. doi:10.1016/j.wneu.2017.09.089

24. Vakharia VN, Sparks R, O'Keeffe AG, et al. Accuracy of intracranial electrode placement for stereoencephalography: a systematic review and meta-analysis. Epilepsia. 2017;58(6):921-932. doi:10.1111/epi.13713

25. Abhinav K, Prakash S, Sandeman DR. Use of robot-guided stereotactic placement of intracerebral electrodes for investigation of focal epilepsy: initial experience in the UK. Br J Neurosurg. 2013;27 (5):704-705. doi:10.3109/02688697.2013.798859

26. Sparks R, Vakharia V, Rodionov R, et al. Assessment of a micro-guided robotic system for seeg electrode placement in a skull phantom. American Epilepsy Society Annual Meeting; December 15; 2017; Washington, DC.

27. Duncan J. A randomised control trial of SEEG electrode placement methods. ISRCTN Registry. 2018. Available from: http://www.isrctn. com/ISRCTN17209025. Accessed June 18, 2019.

28. Lefranc M, Capel C, Pruvot AS, et al. The impact of the reference imaging modality, registration method and intraoperative flat-panel computed tomography on the accuracy of the ROSA(R) stereotactic robot. Stereotact Funct Neurosurg. 2014;92(4):242-250. doi:10.1159/ 000362936

29. Cardinale F, Cossu M, Castana L, et al. Stereoelectroencephalography: surgical methodology, safety, and stereotactic application accuracy in 500 procedures. Neurosurgery. 2013;72(3):353-366.

30. Sparks R, Zombori G, Rodionov R, et al. Automated multiple trajectory planning algorithm for the placement of stereo-electroencephalography (SEEG) electrodes in epilepsy treatment. Int J Comput Assist Radiol Surg. 2017;12(1):123-136. doi:10.1007/s11548-016-1452-x
31. Taussig D, Montavont A, Isnard J. Invasive EEG explorations. Neurophysiol Clin. 2015;45(1):113-119. doi:10.1016/j.neucli. 2014.11.006

32. McGovern RA, Ruggieri P, Bulacio J, Najm I, Bingaman WE, Gonzalez-Martinez JA. Risk analysis of hemorrhage in stereo-electroencephalography procedures. Epilepsia. 2019;60 (3):571-580. doi:10.1111/epi.2019.60.issue-3

33. Arya R, Mangano FT, Horn PS, Holland KD, Rose DF, Glauser TA. Adverse events related to extraoperative invasive EEG monitoring with subdural grid electrodes: a systematic review and meta-analysis. Epilepsia. 2013;54(5):828-839. doi:10.1111/epi.2013.54.issue-5

34. Tandon N, Tong BA, Friedman ER, et al. Analysis of morbidity and outcomes associated with use of subdural grids vs stereoelectroencephalography in patients with intractable epilepsy. JAMA Neurol. 2019. doi:10.1001/jamaneurol.2019.0098

35. Gooneratne IK, Mannan S, de Tisi J, et al. Somatic complications of epilepsy surgery over 25 years at a single center. Epilepsy Res. 2017;132:70-77. doi:10.1016/j.eplepsyres.2017.02.016

36. Garcia-Lorenzo B, Del Pino-Sedeno T, Rocamora R, Lopez JE, Serrano-Aguilar P, Trujillo-Martin MM. Stereoelectroencephalography for refractory epileptic patients considered for surgery: systematic review, meta-analysis, and economic evaluation. Neurosurgery. 2019;84(2):326-338. doi:10.1093/neuros/nyy137

37. Vadera S, Mullin J, Bulacio J, Najm I, Bingaman W, Gonzalez-Martinez J. Stereoelectroencephalography following subdural grid placement for difficult to localize epilepsy. Neurosurgery. 2013;72(5):723-729.

38. Steriade C, Martins W, Bulacio J, et al. Localization yield and seizure outcome in patients undergoing bilateral SEEG exploration. Epilepsia. 2019;60(1):107-120. doi:10.1111/epi.14624

39. Cossu M, Cardinale F, Castana L, et al. Stereoelectroencephalography in the presurgical evaluation of focal epilepsy: a retrospective analysis of 215 procedures. Neurosurgery. 2005;57(4):706-718.

40. Thorsteinsdottir J, Vollmar C, Tonn JC, Kreth FW, Noachtar S, Peraud A. Outcome after individualized stereoelectroencephalography (sEEG) implantation and navigated resection in patients with lesional and non-lesional focal epilepsy. $J$ Neurol. 2019. doi:10.1007/s00415-019-09213-3

41. Youngerman BE, Oh JY, Anbarasan D, et al. Laser ablation is effective for temporal lobe epilepsy with and without mesial temporal sclerosis if hippocampal seizure onsets are localized by stereoelectroencephalography. Epilepsia. 2018;59(3):595-606. doi:10.1111/epi.14004

42. Tao JX, Wu S, Lacy M, et al. Stereotactic EEG-guided laser interstitial thermal therapy for mesial temporal lobe epilepsy. J Neurol Neurosurg Psychiatry. 2018;89(5):542-548. doi:10.1136/jnnp-2017-316833

43. Suresh S, Sweet J, Fastenau PS, Luders H, Landazuri P, Miller J. Temporal lobe epilepsy in patients with nonlesional MRI and normal memory: an SEEG study. J Neurosurg. 2015;123(6):1368-1374. doi:10.3171/2015.1.JNS141811

44. Kubota Y, Ochiai T, Hori T, Kawamata T. Usefulness of StereoEEG-based tailored surgery for medial temporal lobe epilepsy. Preliminary results in 11 patients. Clin Neurol Neurosurg. 2017;158:67-71. doi:10.1016/j.clineuro.2017.04.026

45. Ross L, Naduvil AM, Bulacio JC, Najm IM, Gonzalez-Martinez JA. Stereoelectroencephalography-guided laser ablations in patients with neocortical pharmacoresistant focal epilepsy: concept and operative technique. Oper Neurosurg. 2018;15(6):656-663. doi:10.1093/ons/ opy 106

46. Cobourn K, Fayed I, Keating RF, Oluigbo CO. Early outcomes of stereoelectroencephalography followed by MR-guided laser interstitial thermal therapy: a paradigm for minimally invasive epilepsy surgery. Neurosurg Focus. 2018;45(3):E8. doi:10.3171/2018.6.FOCUS18209

47. Ellis JA, Mejia Munne JC, Wang SH, et al. Staged laser interstitial thermal therapy and topectomy for complete obliteration of complex focal cortical dysplasias. J Clin Neurosci. 2016;31:224-228. doi:10.1016/j.jocn.2016.02.016 
48. Alomar S, Mullin JP, Smithason S, Gonzalez-Martinez J. Indications, technique, and safety profile of insular stereoelectroencephalography electrode implantation in medically intractable epilepsy. J Neurosurg. 2018;128(4):1147-1157. doi:10.3171/2017.1.JNS161070

49. Kahane P, Ryvlin P, Hoffmann D, Minotti L, Benabid AL. From hypothalamic hamartoma to cortex: what can be learnt from depth recordings and stimulation? Epileptic Disord. 2003;5(4) 205-217.

50. Scholly J, Staack AM, Kahane P, et al. Hypothalamic hamartoma: epileptogenesis beyond the lesion? Epilepsia. 2017;58(Suppl 2):32-40. doi:10.1111/epi.13755

51. Wei PH, An Y, Fan XT, et al. Stereoelectroencephalography-guided radiofrequency thermocoagulation for hypothalamic hamartomas: preliminary evidence. World Neurosurg. 2018;114:e1073-e1078 doi:10.1016/j.wneu.2018.03.082

52. Mirandola L, Mai RF, Francione S, et al. Stereo-EEG: diagnostic and therapeutic tool for periventricular nodular heterotopia epilepsies. Epilepsia. 2017;58(11):1962-1971. doi:10.1111/epi.13895

53. Thompson SA, Kalamangalam GP, Tandon N. Intracranial evaluation and laser ablation for epilepsy with periventricular nodular heterotopia Seizure. 2016;41:211-216. doi:10.1016/j.seizure.2016.06.019

54. Schmidt RF, Wu C, Lang MJ, et al. Complications of subdural and depth electrodes in 269 patients undergoing 317 procedures for invasive monitoring in epilepsy. Epilepsia. 2016;57(10):1697-1708. doi:10.1111/epi.13503

55. Wellmer J, von der Groeben F, Klarmann U, et al. Risks and benefits of invasive epilepsy surgery workup with implanted subdural and depth electrodes. Epilepsia. 2012;53(8):1322-1332. doi:10.1111/ j.1528-1167.2012.03545.x

56. Gonzalez-Martinez J, Najm IM. Indications and selection criteria for invasive monitoring in children with cortical dysplasia. Childs Nerv Syst. 2014;30(11):1823-1829. doi:10.1007/s00381-014-2497-1

57. Mo JJ, Hu WH, Zhang C, et al. Value of stereo-electroencephalogram in reoperation of patients with pharmacoresistant epilepsy: a single center, retrospective study. $\mathrm{Br} J$ Neurosurg. 2018;32(6):663-670. doi: $10.1080 / 02688697.2017 .1374348$

58. Bourdillon P, Cucherat M, Isnard J, et al. Stereo-electroencephalography -guided radiofrequency thermocoagulation in patients with focal epilepsy: a systematic review and meta-analysis. Epilepsia. 2018;59 (12):2296-2304. doi:10.1111/epi.14584

59. Bartolomei F, Lagarde S, Wendling F, et al. Defining epileptogenic networks: contribution of SEEG and signal analysis. Epilepsia. 2017;58(7):1131-1147. doi:10.1111/epi.13791

60. Parvizi J, Kastner S. Promises and limitations of human intracranial electroencephalography. Nat Neurosci. 2018;21(4):474-483. doi:10.1038/s41593-018-0108-2

61. Ray S, Crone NE, Niebur E, Franaszczuk PJ, Hsiao SS. Neural correlates of high-gamma oscillations $(60-200 \mathrm{~Hz})$ in macaque local field potentials and their potential implications in electrocorticography. $J$ Neurosci. 2008;28(45):11526-11536. doi:10.1523/ JNEUROSCI.2709-08.2008

62. Kreiman G, Hung CP, Kraskov A, Quiroga RQ, Poggio T, DiCarlo JJ. Object selectivity of local field potentials and spikes in the macaque inferior temporal cortex. Neuron. 2006;49(3):433-445. doi:10.1016/j. neuron.2005.12.019

63. Mukamel R, Gelbard H, Arieli A, Hasson U, Fried I, Malach R. Coupling between neuronal firing, field potentials, and FMRI in human auditory cortex. Science. 2005;309(5736):951-954. doi: $10.1126 /$ science. 1116168

64. Manning JR, Jacobs J, Fried I, Kahana MJ. Broadband shifts in local field potential power spectra are correlated with single-neuron spiking in humans. $J$ Neurosci. 2009;29(43):13613-13620. doi:10.1523/ JNEUROSCI.2041-09.2009

65. Logothetis NK, Pauls J, Augath M, Trinath T, Oeltermann A. Neurophysiological investigation of the basis of the fMRI signal. Nature. 2001;412(6843):150-157. doi:10.1038/35084005
66. Niessing J, Ebisch B, Schmidt KE, Niessing M, Singer W, Galuske RA. Hemodynamic signals correlate tightly with synchronized gamma oscillations. Science. 2005;309(5736):948-951. doi:10.1126/science. 1116168

67. Popa I, Donos C, Barborica A, et al. Intrusive thoughts elicited by direct electrical stimulation during stereo-electroencephalography. Front Neurol. 2016;7:114. doi:10.3389/fneur.2016.00114

68. Zanello M, Pallud J, Baup N, et al. History of psychosurgery at Sainte-Anne Hospital, Paris, France, through translational interactions between psychiatrists and neurosurgeons. Neurosurg Focus. 2017;43(3):E9. doi:10.3171/2017.6.FOCUS17250

69. Youngerman BE, Chan AK, Mikell CB, McKhann GM, Sheth SA. A decade of emerging indications: deep brain stimulation in the United States. J Neurosurg. 2016;125(2):461-471. doi:10.3171/ 2015.7.JNS142599

70. Youngerman BE, Shah S, Sheth SA. DBS for Other Emerging Psychiatric Indications. New York: Thieme; 2019.

71. Widge AS, Deckersbach T, Eskandar EN, Dougherty DD. Deep brain stimulation for treatment-resistant psychiatric illnesses: what has gone wrong and what should we do next? Biol Psychiatry. 2016;79 (4):e9-10. doi:10.1016/j.biopsych.2015.06.005

72. Choi KS, Noecker AM, Riva-Posse P, et al. Impact of brain shift on subcallosal cingulate deep brain stimulation. Brain Stimul. 2018;11 (2):445-453. doi:10.1016/j.brs.2017.12.001

73. ClinicalTrials.gov. Deep Brain Stimulation (DBS) for Depression Using Directional Current Steering and Individualized Network Targeting. Available from: https://clinicaltrials.gov/ct2/show/ NCT03437928. Accessed June 4, 2019.

74. Morrell MJ, Group RNSSiES. Responsive cortical stimulation for the treatment of medically intractable partial epilepsy. Neurology. 2011;77(13):1295-1304. doi:10.1212/WNL.0b013e3182302056

75. Widge AS, Ellard KK, Paulk AC, et al. Treating refractory mental illness with closed-loop brain stimulation: progress towards a patient-specific transdiagnostic approach. Exp Neurol. 2017;287(Pt 4):461-472.

76. ClinicalTrials.gov. Responsive Neurostimulation For Loss Of Control Eating (DBSLOC). Available from: https://clinicaltrials.gov/ct2/ show/NCT03868670. Accessed June 4, 2019.

77. The Brain Initiative. Electrophysiological biomarkers to optimize DBS for depression. Available from: https://braininitiative.nih.gov/ funded-awards/electrophysiological-biomarkers-optimize-dbs-depres sion. Accessed May 20, 2019.

78. Ciganek L, Sramka M, Nadvornik P, Fritz G. Effects of stereotactic operations in the treatment of epilepsies-neurological aspects. Acta Neurochir (Wien). 1976;(23 Suppl):201-204.

79. Munari C, Giallonardo AT, Brunet P, Broglin D, Bancaud J. Stereotactic investigations in frontal lobe epilepsies. Acta Neurochir Suppl (Wien). 1989;46:9-12.

80. So N, Olivier A, Andermann F, Gloor P, Quesney LF. Results of surgical treatment in patients with bitemporal epileptiform abnormalities. Ann Neurol. 1989;25(5):432-439. doi:10.1002/(ISSN)1531-8249

81. Smith JR, Flanigin HF, King DW, et al. An 8-year experience with depth electrodes in the evaluation of ablative seizure surgery candidates. Stereotact Funct Neurosurg. 1990;54-55:60-66.

82. Hirsch LJ, Spencer SS, Williamson PD, Spencer DD, Mattson RH. Comparison of bitemporal and unitemporal epilepsy defined by depth electroencephalography. Ann Neurol. 1991;30(3):340-346. doi:10.1002/(ISSN)1531-8249

83. van Veelen CW, Debets RM. Functional neurosurgery in the treatment of epilepsy in The Netherlands. Aspects of presurgical evaluation and the contribution of subdural and stereotactically implanted depth electrodes in the Dutch Workgroup for functional surgery. Acta Neurochir (Wien). 1993;124(1):7-10. doi:10.1007/BF01400706

84. Espinosa J, Olivier A, Andermann F, Quesney F, Dubeau F, Savard G. Morbidity of chronic recording with intracranial depth electrodes in 170 patients. Stereotact Funct Neurosurg. 1994;63(1-4):63-65. doi:10.1159/000100293 
85. Ross DA, Brunberg JA, Drury I, Henry TR. Intracerebral depth electrode monitoring in partial epilepsy: the morbidity and efficacy of placement using magnetic resonance image-guided stereotactic surgery. Neurosurgery. 1996;39(2):327-333; discussion 333-324.

86. Guenot M, Isnard J, Ryvlin P, et al. Neurophysiological monitoring for epilepsy surgery: the Talairach SEEG method. StereoElectroEncephaloGraphy. Indications, results, complications and therapeutic applications in a series of 100 consecutive cases. Stereotact Funct Neurosurg. 2001;77(1-4):29-32. doi:10.1159/000064595

87. De Almeida AN, Olivier A, Quesney F, Dubeau F, Savard G, Andermann F. Efficacy of and morbidity associated with stereoelectroencephalography using computerized tomography-or magnetic resonance imaging-guided electrode implantation. $J$ Neurosurg. 2006;104(4):483-487. doi:10.3171/jns.2006.104.4. 483

88. McGonigal A, Bartolomei F, Regis J, et al. Stereoelectroencephalography in presurgical assessment of MRI-negative epilepsy. Brain. 2007;130(Pt 12):3169-3183. doi:10.1093/brain/awm218
89. Gonzalez-Martinez J, Bulacio J, Alexopoulos A, Jehi L, Bingaman W, Najm I. Stereoelectroencephalography in the "difficult to localize" refractory focal epilepsy: early experience from a North American epilepsy center. Epilepsia. 2013;54(2):323-330. doi:10.1111/epi.2013.54.issue-2

90. Serletis D, Bulacio J, Bingaman W, Najm I, Gonzalez-Martinez J. The stereotactic approach for mapping epileptic networks: a prospective study of 200 patients. J Neurosurg. 2014;121 (5):1239-1246. doi:10.3171/2014.8.JNS131991

91. Gonzalez-Martinez J, Mullin J, Vadera S, et al. Stereotactic placement of depth electrodes in medically intractable epilepsy. $J$ Neurosurg. 2014;120(3):639-644. doi:10.3171/2013.11.JNS1 3635

92. Taussig D, Chipaux M, Lebas A, et al. Stereo-electroencephalography (SEEG) in 65 children: an effective and safe diagnostic method for pre-surgical diagnosis, independent of age. Epileptic Disord. 2014;16 (3):280-295.

93. Cossu M, Fuschillo D, Casaceli G, et al. Stereoelectroencephalographyguided radiofrequency thermocoagulation in the epileptogenic zone: a retrospective study on 89 cases. $J$ Neurosurg. 2015;123 (6):1358-1367. doi:10.3171/2014.12.JNS141968

\section{Publish your work in this journal}

Neuropsychiatric Disease and Treatment is an international, peerreviewed journal of clinical therapeutics and pharmacology focusing on concise rapid reporting of clinical or pre-clinical studies on a range of neuropsychiatric and neurological disorders. This journal is indexed on PubMed Central, the 'PsycINFO' database and CAS, and is the official journal of The International Neuropsychiatric Association (INA). The manuscript management system is completely online and includes a very quick and fair peer-review system, which is all easy to use. Visit http://www.dovepress.com/testimonials.php to read real quotes from published authors. 